\title{
Welfare, inequality and financial consequences of a multi-pillar pension system. A reform in Peru
}

\author{
Javier Olivera* \\ Department of Economics, \\ Catholic University of Leuven
}

June 16, 2009

\begin{abstract}
The distributional impact of the structural pension reform in Latin American countries has been largely absent in the economic debate. However, this reform may widen inequality in old-age and reduce welfare. In this paper we study the consequences of implementing a multi-pillar system in one of these countries. We take advantage of available administrative records for Peruvian workers to estimate inequality in pensions, pension debt and welfare. Overall, our results show that the pension debt and inequality can be substantially reduced without welfare losses. Thus, the proposed multi-pillar system allows recovering the principle of solidarity and saves fiscal resources.
\end{abstract}

JEL classification: H55, H63, I30, G23.

Keywords: Pension reform, pension inequality, social security, Latin America, Peru.

*I am grateful to Erik Schokkaert for his helpful comments and to the Economic and Social Research Consortium of Peru for supporting financially an earlier report (Project ACDI-IDRC 2007-PM 35).

E-mail address: javier.olivera@econ.kuleuven.be Address: Naamstraat 69, Leuven. 3000. Belgium. Fax: +3216326796. Telephone: +3216326654 . 


\section{Introduction}

Following the Chilean pension reform of 1981, a number of Latin American countries transformed during the 90's their public pension systems into private individual capitalization systems. Some countries completely replaced their old pension system by a system based on individual capitalization and privately managed (Bolivia, Chile, Dominican Republic, El Salvador and Mexico). Others kept the public system which competes with the new private system (Colombia and Peru) whilst other countries assigned the role of first pillar to the public system and created a private system as a second pillar (Argentina, Costa Rica and Uruguay) in an integrated system. These models are categorized as substitutive, parallel and mixed, respectively (Arenas de Mesa \& Mesa-Lago, 2006).

The emphasis of this reform was on the spillovers in the financial markets, public debt and growth. Furthermore, economic research and debate are concentrated in those issues and some important aspects such as fees levels, competition and enrolment rates. As it is stressed in Arza (2008) and Barr \& Diamond (2009) there is little analysis on distributional and welfare consequences. However, these effects may be large and even intensify inequality in those countries; specially if we take in account that only a small fraction of population is covered by the pension system (see last column of table 1).

Table 1

Some indicators by country

\begin{tabular}{|c|c|c|c|c|c|c|c|}
\hline \multirow[b]{2}{*}{ Country } & \multirow[b]{2}{*}{$\begin{array}{l}\text { Reform } \\
\text { Year }\end{array}$} & \multicolumn{4}{|c|}{ Gini coefficients } & \multirow[b]{2}{*}{$\begin{array}{c}\text { Fiscal cost } \\
(\% \text { GDP) }\end{array}$} & \multirow[b]{2}{*}{$\begin{array}{l}\text { Coverage } \\
(\% \text { of EAP) }\end{array}$} \\
\hline & & $\begin{array}{l}\text { Survey } \\
\text { Year }\end{array}$ & $\begin{array}{c}\text { Labour } \\
\text { income }[\mathrm{a}]\end{array}$ & $\begin{array}{c}\text { Pensions } \\
{[\mathrm{b}]}\end{array}$ & $\begin{array}{c}\Delta \text { in Gini } \\
\text { [a-b] }\end{array}$ & & \\
\hline Argentina & 1994 & 2006 & 0.444 & 0.336 & 0.108 & -2.5 & 20.7 \\
\hline Bolivia & 1997 & 2005 & 0.562 & 0.259 & 0.303 & -3.5 & 10.5 \\
\hline Colombia & 1994 & 2004 & 0.513 & 0.405 & 0.108 & -1.6 & 22.2 \\
\hline Costa Rica & 2001 & 2006 & 0.454 & 0.559 & -0.105 & 0.0 & 46.6 \\
\hline Dominican Rep. & 2003-2006 & 2006 & 0.484 & 0.486 & -0.002 & n.a. & 14.5 \\
\hline El Salvador & 1998 & 2005 & 0.468 & 0.392 & 0.076 & -1.4 & 20.1 \\
\hline Mexico & 1997 & 2006 & 0.509 & 0.489 & 0.020 & -0.5 & 28.0 \\
\hline Peru & 1993 & 2006 & 0.519 & 0.339 & 0.180 & -0.7 & 12.0 \\
\hline Uruguay & 1996 & 2005 & 0.501 & 0.449 & 0.052 & -4.0 & 58.8 \\
\hline
\end{tabular}

Given that the pension based on individual capitalization is a direct function of labour income, the reformed pension system reproduces labour income differences into pensions. In this sense, the potential amplification of inequality during old-age may be approximated by the difference between the Gini coefficients for labour income and pre-reform pensions. In general, there is scarce information about inequality measures for pensions in Latin American countries, and in particular it is hard to get this information for the pre-reform period. The only available cross-country Gini coefficients for pensions date to 2004-2006. Since the majority of reforms 
occurred in mid 90's, the largest part of pensioners still hold a pension entitled during the prereform system; therefore, the difference between the Gini coefficients shown in table 1 give us an idea on how inequality from labour market can be transmitted to old-age. In almost all countries there is a threat of wider pension inequality, with Bolivia, Peru, Argentina and Colombia being the countries that might face the most dramatic change in inequality during oldage ${ }^{1}$.

By combining inequality in pension coverage and benefits computed under individual capitalization in some hypothetical pension designs, Arza (2008) also stresses the transmission and exacerbation of inequality of the Latin American pension systems. Although that exercise and our previous table highlight the potential distributional consequences of pension reforms in Latin America, it is still necessary to analyse more precisely inequality in pensions and how this interplays with other policy objectives. As we may infer from the large yearly Government transfers to pay pensions, shown in table 1, the reduction of pension debt is a main objective for policy-makers from these countries. Making clear the trade-offs between inequality, pension debt and welfare stresses the different roles of pension policies and it might be more appealing for policy-makers. Indeed, on the basis of this sort of study we might be able to draw plausible and reliable policy recommendations and show their possible consequences in many dimensions. However, this is quite demanding on specific information such as administrative records of workers and pensioners, which is hardly available and disclosed by governmental authorities.

Although it would be ideal to make this analysis in a cross-country fashion, one study case may provide enough insights to highlight the distributional consequences of pension reform and policies aimed to alleviate it, and also encourage more detailed research on these topics. In this way, we take advantage of unique administrative data samples of Peruvian workers to measure the consequences of pension reform in inequality, welfare and pension debt; and most importantly, studying the effects of a proposal for reforming the current Peruvian pension system in into a multi-pillar system.

In the next section we outline the Peruvian pension system, and then the reform proposal is presented together with the methodology to estimate pensions and pension debt. Section 4 is devoted to present and discuss the effects of the reform on pension debt, inequality and welfare; and the paper finalizes with some concluding remarks. 1 Inequality in pensions in Costa Rica is notably higher than that in labour income. However, this difference
disappears when we use data surveyed in 2002 from the Costa Rican national statistical institute. 


\section{An outlook of the Peruvian pension system}

Peru created in 1993 the Private Pension system (SPP), which is a system based on individual capitalization, without dismantling its old defined benefit system (the National Pension System, SNP) ${ }^{2}$. Workers have to choose only one of these two systems. If SNP is chosen, the insured is able to shift to SPP later on, but the contrary is not permitted. An individual who chooses the SPP, must also enrol in one of the firms that administrate pension funds (AFP). If an insured moves from SNP to SPP, the State entitles a recognition bond (BR) as a way to compensate for the contributions made to SNP, but only if some legal requirements are fulfilled. In general, the SNP may be preferred by low income earners, who might obtain at least a minimum pension, whilst the SPP may be favoured by medium and high income workers.

The insured of the SPP (those who previously belonged to the SNP) realized that the expected or already received benefits in the SPP were lower than those in the SNP. Indeed, they could obtain at least a minimum pension in the SNP, which is not guaranteed in the SPP. Many of these insured shifted to SPP, expecting to receive a large BR and capitalize more contributions in the pension fund system with the aim to reach better pensions. However, these insured either failed to fulfil legal requirements to receive a BR or its final value was much under insured's expectation. Additionally, a large number of these individuals were not young enough to capitalize their contributions; and worst, they could acquire an early or normal retirement benefit in the SNP if they had remained there. In order to correct these negative effects of the reform, there have been many adjustments in the pension system; for instance, the recent Law 28991 (under restricted circumstances the insured can return to the SNP) and the creation of special regimes (e.g. early retirement for long-term unemployed and workers in high-risk occupations) ${ }^{3}$. Implicitly, all these changes represent the recognition by the Government of contributions paid by the workers to the old public system. This debt acknowledge is accounted in complementary recognition bonds, and therefore leads to increase the public debt even more.

In some way, the expectations of the SPP's insured, previously enrolled in the SNP, to receive benefits similar to those in the SNP can be achieved with the mentioned adjustments. However, there are two groups of insured who potentially would demand better benefits, and hence more fiscal resources. The first one is the group of low-income insured of the SPP who are not able to capitalize enough to reach a pension that meets their needs in old-age. Although in practice there is no minimum pension in the SPP, it is expected that insured of the SPP still look at the

\footnotetext{
${ }^{2}$ The SPP is supervised by the Superintendence of Banking and Insurance (SBS), whilst that the SNP is administrated by the Bureau of Pensions (ONP).

${ }^{3}$ The minimum pension was also regulated, but only for a small group of insured. Contrary to the SNP, the SPP does not offer an open minimum pension. This guarantee was only reachable for individuals born before 1945, with earnings larger than or at least equal to the minimum legal income and 20 years of contributions made to any pension system. Law 28891 abolished the birth requisite in March 2007 but the minimum pension was restricted to persons that shifted from SNP to SPP.
} 
SNP's minimum pension as a reference point to demand higher pensions. The other group is composed of the current and future insured of the SNP. The creation of the SPP attracted a considerable number of insured from the SNP and new workers who preferred to enrol in the new system. This, in turn, weakened the financial sustainability of the SNP, which depends on the dependency ratio. Under current parameters, the dependency ratio should be 4.4 contributors for each pensioner in order to keep the system balanced; however, this ratio is only $1.3^{4}$. This is one of the explanations for the large actuarial reserve, which amounts to US $\$ 26$ billion, i.e. $23 \%$ of GDP. It must be mentioned that this considerable debt corresponds only to pensioners and insured of the SNP, who represent a small fraction of Peruvian population $7.4 \%$ of total population).

The reform has generated a considerable debt. Apart from the large actuarial reserve in the SNP, there is US $\$ 4,700$ million corresponding to recognition bonds. Furthermore, the implementation of Law 28891 represents a fiscal cost of US\$2,137 billion in actuarial terms (MEF, 2008). Since these figures are expressed in current and actuarial terms, they cannot be aggregated, although they are useful to highlight the significant size of the pension debt (see table 2). One could consider that fiscal spending on pensions is worth it due to its positive effects on preventing old people falling into poverty, but this is not necessarily the case in Peru. Only salaried employees of the formal sector are obligated to enrol in the pension system, which means that self-employed, employers and other types (in the formal or informal sector) can choose voluntary enrol or not. Since the informal sector in Peru is huge and incomes are low, pension enrolment is not a choice at all for these workers; and hence the enrolment rate is small ${ }^{5}$. It means that the overall pension debt has no effect on preventing poverty for an important fraction of the population. Those who are not enrolled in the pension system have to rely on family solidarity during old-age.

Table 2

Pension debt (2007, US\$ million)

\begin{tabular}{|c|c|c|c|}
\hline In current terms & & In actuarial values & \\
\hline Recognition bonds a/ & 4,230 & Law $28891 \mathrm{c} /$ & 2,137 \\
\hline Compl. recognition bonds b/ & 448 & SNP 's Actuarial net reserve d/ & 25,887 \\
\hline
\end{tabular}

\footnotetext{
${ }^{4}$ The Government may modify parameters and pension rules, but within reasonable limits. But the imbalance is so large that this policy is not effective. For instance, if the contribution rate is the unique adjustable parameter, this would rise up to the impracticable rate of $43.8 \%$ to balance the system.

${ }^{5}$ According to ILO (2009), 55\% of the Peruvian urban labour force was informal in 2007. This definition of informal includes the non professional self-employed, unpaid family workers, employers and employees working in firms with less than 6 workers and domestic workers. $44.8 \%$ of labour force is enrolled in the SPP or SNP, but only $18.7 \%$ contributes regularly.
} 
The creation of the SPP broke the principle of solidarity, a key element for redistribution and financing of pensions. Before reform, the system design allowed to finance pensions from richer to poorer, young to elder, healthy to disabled, etc 6 . Looking for policy options, we favour the recommendations made by the World Bank (Holzmann et al, 2005; World Bank, 1994) to create a multi-pillar pension system, based on three pillars: i) a mandatory public pillar, ii) a funded pillar with mandatory individual capitalization accounts, and iii) a funded pillar with voluntary individual accounts. Under the first pillar, all insured receive a minimum or basic pension. The second pillar allows insured to capitalize contributions according to his income level. The goal of the third one is to allow the insured to further raise his expected pension if he is able to save more. The next section develops a proposal to create a multi-pillar pension system in Peru.

\section{A reform proposal}

\subsection{Description}

We propose to implement a multi-pillar pension system by merging the SNP and SPP. The number of years contributed to any system up to the reform date must be accounted for the evaluation of the entitlement of a minimum pension. Additionally, the insured of the SPP are allowed to keep their pension balance. In the new system each insured has to contribute a rate $\alpha$ from his wage to his individual account and a rate $\beta$ to the solidarity fund. The aim of this fund is financing the minimum pension scheme. The requisites to obtain a minimum pension are the same as in the SNP: i) 20 years of contributions (to SNP and/or SPP), and ii) the wage used to calculate the contribution must be, at least, equal to the minimum wage.

At the retirement age, the pension is computed with the pension balance. If the pension is lower than the minimum pension, then additional resources are added from the solidarity fund until the pension equals the minimum pension value. This means that this guarantee is targeted and redistributive. It is targeted because it is directed only to individuals who are unable to finance a pension higher than that guarantee with their own pension balance. And it is redistributive because the contributions from high income workers are used to finance minimum pensions for low income workers.

In addition, the reform is intended to reduce the pension debt, which in turn may improve fiscal spending allocation. The State has to assign significant resources to pay pension obligations, which might otherwise be used for other social programs ${ }^{7}$. It means that tax revenues -that are paid by pension enrolled and not enrolled workers- are used to pay pensions, which reinforces inequality (Arza, 2008). This is particularly critical due to the fact that the

\footnotetext{
${ }^{6}$ Furthermore, without solidarity is not possible to finance benefits for a larger population i.e. promoting universality (Titelman y Uthoff, 2003).

7 Only in 2007, the SNP's pension roll assumed by the State was S/. 2,455 million, i.e. $0.73 \%$ of the GDP.
} 
group of pension enrolled is much more advantaged than the non-enrolled. The former work in the formal sector, have higher and more stable incomes and better education, etc.

We simulate the reform, first by estimating the pensions of the insured of both systems (with and without reform) and second, by computing the corresponding actuarial reserves ${ }^{8}$. The pensions and actuarial reserve for the multi-pillar system are computed using different values for $\alpha$ and $\beta$. For comparison reasons, we must choose values for $\alpha$ and $\beta$ such that $\alpha+\beta=0.10^{9}$. Thus, we obtain different pension distributions and actuarial reserves, which allows us to make welfare and inequality comparisons. In the simulations, the enrolment of new workers is not considered but we allow for the death of insured.

\subsection{Data}

One important advantage of this study is the availability of administrative records. We use two representative samples of the insured registered up to December 2006 in the SPP and SNP; so the simulations are made to that date. The samples contain information on wage, age, gender, age of enrolment in the SPP, pension balance, BR value and its corresponding number of contributions. The sample of the SPP is random and stratified according to gender, age group (group of 5 years) and age of enrolment. Although the sample originally consisted of 65,534 records, 337 people were removed with inconsistent information. A significant number of insured had no information on wages, so that these were also dropped, leaving a final sample of 31,719 individuals (see table 3).

Table 3

Sample of insured (December 2006)

\begin{tabular}{|c|c|c|}
\hline & SPP & SNP \\
\hline Population & $3,882,185$ & $1,329,510$ \\
\hline Sample & 31,719 & 26,168 \\
\hline$\leq 65$ years old & $31,534 \quad(0.818 \%)$ & $24,992 \quad(1.970 \%)$ \\
\hline$>65$ years old & $185 \quad(0.628 \%)$ & $1,176 \quad(1.935 \%)$ \\
\hline
\end{tabular}

The sample of the SNP is also random and stratified by gender and age group. The original sample consisted of 26,589 individuals, i.e. $2 \%$ of the population enrolled up to December 2006, but 59 records of individuals with not trustable information were removed ${ }^{10}$. After we dropped individuals without wage information, the sample was finally composed of 26,168 records.

\footnotetext{
${ }^{8}$ We treat a change in the actuarial reserve as equivalent to a change in the pension debt in the same magnitude.

${ }^{9}$ The contribution rate in the SPP and SNP is $10 \%$ and $13 \%$ of salary, respectively. In addition, the AFP charges an administrative fee and collects the insurance premium that covers the risks of disability and death. The fee and insurance premium are $1.81 \%$ and $0.88 \%$ on average, respectively. Overall, the insured of the SPP and SNP pay a rather similar percentage of their wage.

${ }^{10}$ Those aged under 18 or over 90 years old or earning more than S/. 100,000 a month.
} 
It should be noted that for computational purposes, the value of monthly wage was changed for some individuals. This has to be at least equal to minimum wage (S/.500 per month in 2006); thus we set the wage up to that amount for those individuals who had a lower wage. The reason is that in both systems, workers must make contributions based on a wage equal or higher than the minimum wage. This wage adjustment is also carried out by the ONP when it computes the actuarial reserve of the SNP.

We also estimated the enrolment age of the SNP's insured since this variable is not included in our sample. We use the database PRIESO to estimate the enrolment age in the SNP ${ }^{11}$ for males and females. The dependent variable was the enrolment age and the independents were the current age (at May 2002) and its square. The corresponding coefficients were used to impute the enrolment age for the individuals of our SNP sample. We prefer this method to that of assuming a fixed number of contributions for all insured (which is used by the ONP to calculate the SNP's actuarial reserve) because there are important differences in the enrolment age due to the gender and cohort. According to our estimations, males enrolled between 18 and 26 years old, regardless current age. In contrast, old cohorts of females enrolled much older than young cohorts of females.

\subsection{Computation of pensions and simulation of the actuarial reserve}

The computation of pensions in the SNP follows the pension rules of that system, whilst in the SPP and the proposed multi-pillar system the pensions are computed by using a simple capitalization process and the standard parameters are involved (e.g. annuity price, mortality, discount and return interest rates). The appendix deals with these computations.

The actuarial reserve is the capital needed to address the payment of current and future pensions. This payment is contingent to the death date of current and future insured and pensioners; therefore the probability of death (from mortality tables) and a discount rate must be taken into account. In a defined benefit system like the SNP and in a multi-pillar system as we propose, these payments should be compared with the present value of contributions in order to know the final balance: deficit, equilibrium or surplus. The appendix shows the methodology used to estimate the actuarial reserve in the SNP, SPP and multi-pillar system.

11 The "Social Risk Management Survey" (PRIESO) is a household survey combined with a large scale field experiment conducted by the World Bank in Lima Metropolitana during May 2002. The database contains 1,002 individuals randomly chosen from the respondents of the National Household Survey (ENAHO), which was applied during the third quarter of 2001. See Barr and Packard (2005) for more details on this survey. 


\subsection{Parameters}

\section{i. Mortality}

It is important to note that Peru uses three different mortality tables, and all make a distinction by gender. The SPP does not have its own tables, it has always used Chilean tables. Until 2006, the SPP used the complete set of Chilean tables built in 1985. Since that date, the tables used are also Chilean but built with information from 200412. Currently, the 2004 tables are used to calculate the annuity price for pension holders, while the 1985 tables are still used to calculate the annuity price for disabled persons and beneficiaries. Differently, the ONP used the 1985 Chilean tables until 2006 to estimate the actuarial reserves in the SNP. But since 2007 it uses mortality tables built with Peruvian data (SP-2005) ${ }^{13}$. It is paradoxical that the SPP does not use the table SP-2005, despite reflecting (in theory) the real mortality profile of the Peruvian insured.

In order to compare actuarial reserves, it is necessary to use the same mortality tables in all cases. Thus, we adopt the tables currently used in the SPP, i.e. the RV-2004 for pension holders and the B-85 for beneficiaries. In all these tables, the maximum age of survival is $M=110$. Regarding the number and type of beneficiaries, it is assumed that each insured has a spouse and none not-adult child. It is also assumed that the age difference between spouses is 4 years, and always in favour of males ${ }^{14}$.

\section{ii. Interest rates}

Since our simulation of actuarial reserves implicitly assumes no inflation, the interest rate is assumed free of price changes. Furthermore, this should be a long-term rate given the long period a person contributes. The pension fund's yearly real return since the start of SPP, i.e. August 1993, to each subsequent year varies between 6.3\% and $11.7 \%$; and the average is $8.2 \%$. In contrast, the yearly return of the fund (Consolidated Fund of Reserves, FCR, which is in dollars) used to pay benefits in the SNP varies between $2.8 \%$ and $9.5 \%$; with $5.5 \%$ as average rate. Instead, it is also possible to calculate the pension fund's yearly real return during the last 5 or 10 years at each month. In this exercise, the average rate is $9.3 \%$ whatever the periodicity, although the range of variation is between $4.0 \%$ and $20.9 \%$ or $7.1 \%$ and $12.2 \%$ for the 5 and 10 year period, respectively.

The estimation of pensions and actuarial reserves is very sensitive to the value of the return rate. While in the 15 years of operation of the SPP, the average real return is about $9 \%$, it is best to assume a conservative value. Therefore, let's assume $\tilde{r}=6 \%$. This same value is assumed in

12 The 1985 tables are RV-85, MI-85 and B-85, for pension holders, beneficiaries and disabled persons respectively. The 2004 tables are named RV-2004.

13 The Chilean MI-85 table is still used in the SNP for disabled persons.

14 The average age difference between the heads of household under 65 years and their wives is 3.6 according to the National Household Survey (ENAHO-2006). MEF (2008) also assumes that the spouse is the sole beneficiary, but with an age difference of 5 years, while in Bernal et al (2008) this difference is 3 years. 
other studies that show long-term projections for the Peruvian pension system, as is the case of Moron and Carranza (2003) and Bernal et al (2008).

According to available data, the gross average of the annuity's discount interest rate ranges between $4.7 \%$ and $4.9 \% 15$. In contrast, the discount interest rate used by the AFP to calculate scheduled withdrawals, that is another type of pension, is between $4.06 \%$ and $4.10 \%$. The AFP have kept these values since October 2003. Furthermore, the interest rate specified in the regulation for evaluating the entitlement of some benefits (e.g. regular and special early retirement and minimum pension) is $4.6 \%$. Therefore, given that there is not much discrepancy among all these values, we assume $\hat{r}=4.6 \%$ in our simulations.

The discount interest $(r)$ rate is needed to find the present value of a life annuity, and consistently we must use the same interest to estimate the actuarial reserve and present value of contributions, hence $r=\hat{r}=4.6 \%$. Other authors that estimate pension debt for Latin American countries use similar rates; Zvinieni and Packard (2002) use a discount rate of 4\%, Holzmann et al (2004) use values between $2 \%$ and $5 \%$. A discount rate of $4 \%$ is used by other authors that estimate actuarial reserves in Peru (MEF, 2008 and Bernal et al, 2008). The ONP also uses $4 \%$ to estimate the actuarial reserves of the SNP.

\section{iii. Parameters of the pension systems}

Since 1998, the SBS publishes monthly a proxy for the density of contributions in the SPP, which is defined as the quantity of contributors over the total of insured, excluding those who never contributed to the SPP. The mean of this indicator was 51.1\% between January 1998 and August 2008. Although this variable is not calculated in the SNP, we can construct a proxy by using the information available in the ONP's summary of annual economic study of pension reserves. The average yearly ratio between contributors and insured in the SNP was $47.1 \%$ between 2000 and 2007. Given the unavailability of information on contribution density neither at individual level nor for future and past periods, it is assumed for simplicity that all insured of the SPP, SNP and multi-pillar had and will have a density contribution of $50 \%{ }^{16}$. This assumption is not far from more accurate figures estimated in other funded pension systems such as in Chile and Argentina (Arenas de Mesa et al, 2008; Bertranou and Sánchez, 2003). For the SPP, MEF (2008) uses a contribution density of $60 \%$ but this value is too optimistic and does not have a clear empirical base.

The minimum pension for the insured in the SPP and SNP is S/.484 a month. The SNP also offers a minimum pension for beneficiaries (the insured's spouse), which is S/.315. All these

15 This figures correspond to annuities (life, deferred and guaranteed) in Dollars and obtained at the legal retirement age in Dec-2006, Dec-2007 and Oct-2008. The information on annuities in Dollars is enough to have an idea on the value of the interest rate because the majority of retirees choose this currency (around $98 \%$ of the annuities were given in Dollars).

16 In terms of the computation of pensions (in the appendix) it means that $t_{0}^{s n p}=t_{1}^{s n p}=t_{0}^{s p p}=t_{1}^{s p p}=t_{1}^{\text {mix }}=50 \%$. 
same values are assumed for the multi-pillar system. Moreover, the maximum pension offered in the SNP is $S / .1,000$. In the SNP, the widow always receives a survival pension $(50 \%$ of the spouse's pension) but the widower receives such a pension only if he is disabled or has more than 60 years and depended economically on his wife. In the simulation of SNP reserves, $\theta_{s n p}=50 \%$ and it is assumed that survival pensions are only entitled to widows. In the SPP and multi-pillar system, $\theta_{s p p}=\theta_{m i x}=42 \%$ for widows and widowers.

\section{Effects of the reform}

\subsection{Actuarial reserve}

The estimation of the actuarial reserve is extremely sensitive to assumptions, pension rules and parameters. The evolution of the SNP's reserve not only responds to the dynamic of pensions, incomes, contributors and pensioners, but also to some changes in the estimation methodology (see table 4). For instance, since 2007 the ONP uses the mortality table SP-2005, which assumes higher longevity ${ }^{17}$, instead of the RV-85.

Table 4

Actuarial reserve of SNP (US\$ millions)

\begin{tabular}{|c|c|c|c|c|c|c|}
\hline Year & $\begin{array}{l}\text { Pensioners } \\
\text { (a) }\end{array}$ & $\begin{array}{l}\text { Insured } \\
\text { (b) }\end{array}$ & $\begin{array}{c}\text { Total } \\
\text { (a)+(b) }\end{array}$ & $\begin{array}{l}\text { Present value } \\
\text { of contrib. (c) }\end{array}$ & $\begin{array}{l}\text { Net reserve } \\
\text { (a)+(b)-(c) }\end{array}$ & (b)-(c) \\
\hline \multicolumn{7}{|c|}{ ONP estimation: } \\
\hline 2000 & 5,672 & 12,518 & 18,190 & 4,787 & 13,403 & 7,731 \\
\hline 2001 & 7,739 & 13,027 & 20,766 & 5,249 & 15,517 & 7,778 \\
\hline 2002 & 7,598 & 12,531 & 20,129 & 4,978 & 15,151 & 7,553 \\
\hline 2003 & 7,988 & 13,418 & 21,406 & 5,680 & 15,726 & 7,738 \\
\hline 2004 & 8,846 & 15,449 & 24,295 & 6,579 & 17,717 & 8,870 \\
\hline 2005 & 9,390 & 16,239 & 25,629 & 7,142 & 18,487 & 9,097 \\
\hline 2006 & 10,606 & 19,318 & 29,924 & 9,360 & 20,564 & 9,958 \\
\hline 2007 & 12,653 & 24,272 & 36,924 & 11,038 & 25,887 & 13,234 \\
\hline \multicolumn{7}{|c|}{ Author's estimation: } \\
\hline 2006 & n.a. & 14,255 & & 4,550 & & 9,704 \\
\hline
\end{tabular}

Moreover, in table 4 there are striking differences between the results of our estimation and ONP's. The main reasons for this discrepancy are i) a discount rate for the actuarial reserve and annuity price equals to $4.6 \%$, while the ONP uses $4 \%$; ii) contribution density is $50 \%$, which implies an average of 20.9 years contributed in our SNP sample; this sharply contrasts with the 33 years supposed by the ONP18; iii) the mortality table used is RV-2004 instead of the RV-85; iv) not inclusion of the insured without age information in the SNP sample; while the ONP supposes they are 41 and 43 years old; v) the age difference between spouses is 4 years while

17 According to table SP-2005, 65 year old males and females are expected to live 18.06 and 24.79 additional years, respectively. In contrast, table RV-85 forecasts 17.15 and 20.71 for males and females, respectively.

18 Until 2006, the ONP assumed that insured contribute up to 33 years; but since 2007, it is 27 years. 
the ONP assumes 7 years. It is worth mentioning that the simulation uses the same exchange rate by ONP in 2006, i.e. S/.3.194 per Dollar.

The actuarial reserve for current SNP's pensioners is not estimated because the proposed reform will not affect current pensions and therefore will not change this reserve. Accordingly, the concept of net reserve will be henceforth the difference between the actuarial reserve of insured workers and the present value of their contributions. This is precisely the concept expressed in the last column of Table 4. Our estimation is US\$9,704 billion (10.4\% of GDP), not far from ONP's. We must add to this amount the reserve of minimum pensions offered to some insured in the SPP in order to obtain the actuarial reserve of the pension system as a whole. Thus, before any reform the actuarial reserve amounts to US $\$ 10,296$.

Table 5

Pension debt with and without reform (US\$ million)

\begin{tabular}{|c|c|c|c|c|c|c|c|c|c|}
\hline No Reform & & & & & & & & & \\
\hline a. Present value of contributions & 4,550 & & & & & & & & \\
\hline b. Reserve for SNP insured & 14,255 & & & & & & & & \\
\hline c. Reserve for SPP insured & 592 & & & & & & & & \\
\hline d. Net reserve: $c+b-a$ & 10,296 & & & & & & & & \\
\hline \multirow{2}{*}{ With Reform } & \multicolumn{9}{|c|}{ Contribution rate to individual account } \\
\hline & $\alpha=1 \%$ & $\alpha=2 \%$ & $\alpha=3 \%$ & $\alpha=4 \%$ & $\alpha=5 \%$ & $\alpha=6$ & $\alpha=7 \%$ & $\alpha=8 \%$ & $\alpha=9 \%$ \\
\hline e. Present value of contributions & 20,763 & 18,456 & 16,149 & 13,842 & 11,535 & 9,228 & 6,921 & 4,614 & 2,307 \\
\hline f. Reserve for insured & 21,204 & 19,803 & 18,522 & 17,354 & 16,284 & 15,305 & 14,412 & 13,595 & 12,848 \\
\hline g. Net reserve: f-e & 441 & 1,347 & 2,373 & 3,512 & 4,749 & 6,077 & 7,491 & 8,981 & 10,541 \\
\hline Savings from reform: $d-g$ & 9,855 & 8,949 & 7,923 & 6,784 & 5,547 & 4,219 & 2,805 & 1,315 & -245 \\
\hline
\end{tabular}

Table 5 shows the reform's effect on pension debt under different combinations of contribution rates $\alpha$ and $\beta$, subject to $\alpha+\beta=10 \%$. Each column exhibits the estimated value of the actuarial reserve and the amount of savings for the State due to reform. For instance, in the first column, $9 \%$ of salary is contributed to the solidarity fund and only $1 \%$ to the individual account; i.e. the multi-pillar system would be close to work as a defined benefit system. In this scenario, the pension debt is reduced to only US $\$ 441$ million, so the State may save up to US $\$ 9,855$ million, which is equivalent to $10.5 \%$ of $\mathrm{GDP}^{19}$. Although this is an extreme scenario, it is instructive. If the contribution rate to individual account is higher, as shown in the other columns of the table, the State may still obtain substantial savings. The other extreme case is shown in the last column of table 5. In that scenario the multi-pillar system would be similar to the SPP with only a small contribution rate to the solidarity fund, although with a guaranteed minimum pension scheme. This alternative slightly raises the pension debt by US $\$ 245$ million instead of generating savings.

19 This result implies that the merger of insured from the SPP and SNP alleviates the actuarial deficit; and it also brings support to the idea that the creation of the SPP increased the pension debt in the SNP. 
A social planner only interested in reducing the pension debt will chose the scenario with the lowest contribution rate for the individual account. Although this choice might lead to less inequality among pensioners, it could also imply some adverse consequences in welfare. The next section is devoted to these issues.

\subsection{Equity and welfare}

Apart from reducing the pension debt, the reform also has distributional and welfare effects. The effect on the distribution of pensions is quantified by the Gini coefficient (G). While this indicator is widely used to measure income inequality, its normative characteristics are not explicit. In contrast, the Atkinson index (Atkinson, 1970) is built on an explicit ethical basis since it takes into account the inequality aversion of the planner (Lambert et al, 2008). This index is defined as $\mathrm{I}(e)$; and $e$ is the parameter of inequality aversion of the social planner.

In the context of pension systems, the Atkinson index may be interpreted as the fraction of national income of pensions which can be lost in order to achieve equality in the distribution of pensions. Or in other words, it is the price that the planner is willing to pay for complete equality. If $e \rightarrow 0$, the planner is neutral to inequality and the index tends to zero, thus it is not willing to sacrifice pension amounts in exchange for perfect equality. However, a planner more averse to inequality exhibits an index that tends to 1 , so that it tolerates large losses in the pensions in exchange for greater equality.

With regard to the effects on welfare, the planner should be able to build social welfare functions (SWF) with the resulting pension distributions from the reform, and then rank them. As pointed in Lambert (2001), the SWF must be increasing in the income mean and decreasing in the inequality index. Thus, if $\mu$ indicates the pension mean, then the SWF built with the Gini coefficient and Atkinson index are $\mathrm{W}_{\mathrm{G}}=\mu(1-\mathrm{G})$ and $\mathrm{W}_{\mathrm{I}(e)}=\mu(1-\mathrm{I}(e))$ respectively.

As a result of the simulations we obtain yearly pensions between 2007 and 2050, therefore the average pension and distributional and welfare indexes are also computed by year. Since each generation of pensioners shows different probability of survival through the simulation period, we must use a sort of weight to aggregate pensions of all existing pensioners in each year. This weight is simply the probability of survival from age 65 until each subsequent year, extracted from the mortality table. Figure 1 shows the evolution of the average pension and the corresponding Gini coefficient ${ }^{20}$. The pensions grow through the period as a consequence of the capitalization process, particularly of the younger generation of insured who has more time to capitalize. At the beginning, the pensions computed without reform are higher than those of any

${ }^{20}$ In this figure and henceforth, pension average and inequality and welfare measures refers to insured who retire at 65 years old. 
other reform scenario, but since year 2019 the scenario with $\alpha=9 \%$ shows the highest pensions. In the case of the Gini, the scenario of no reform is always more unequal.

Figure 1

Pension mean and Gini coefficient per year
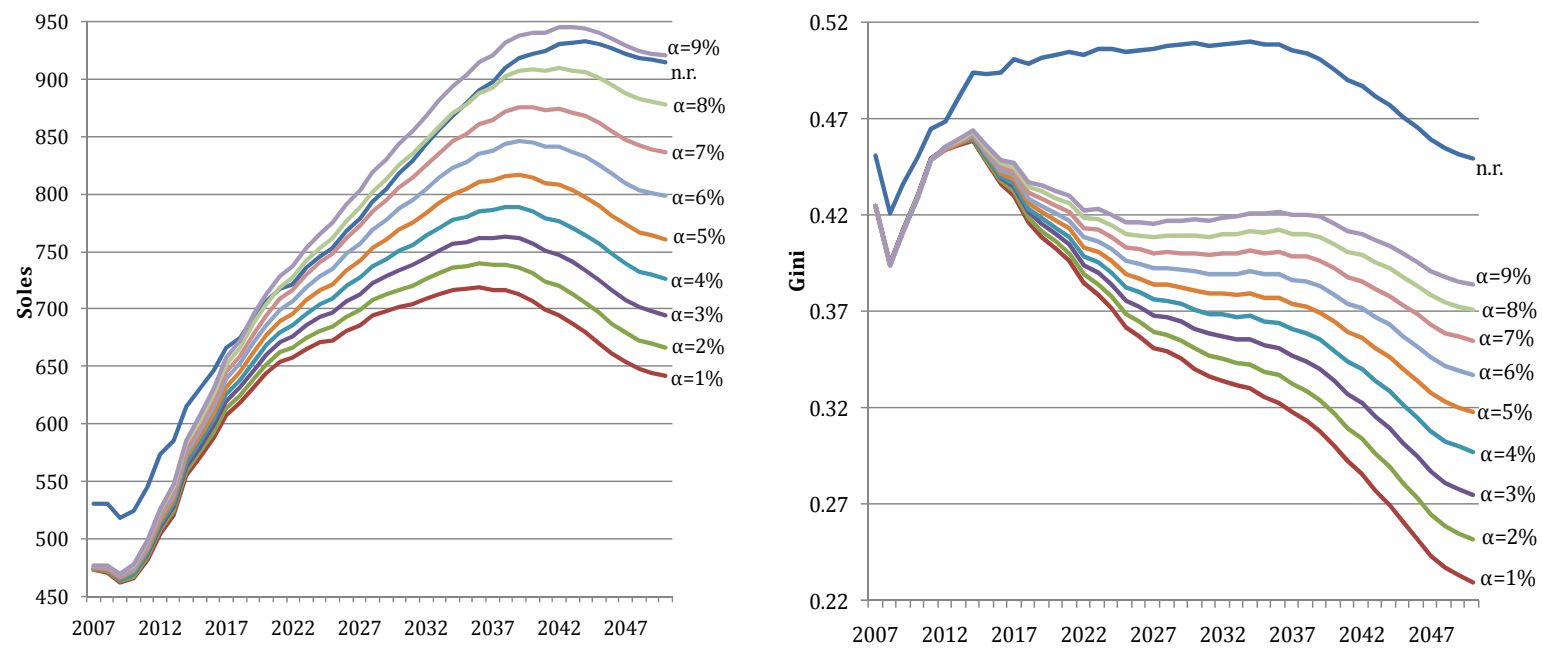

Source: Author's simulation. n.r. = no reform.

In order to ease the comparison of pension distributions from different scenarios and make explicit the trade-offs with the pension debt reduction, we use the averages of the pension mean and inequality and welfare indexes of the whole simulation period ${ }^{21}$. Table 6 shows inequality measures for each pension distribution derived from different contribution rates $\alpha$.

Table 6

Inequality indexes

\begin{tabular}{|c|c|c|c|c|c|c|c|c|c|}
\hline \multirow{2}{*}{ No Reform } & \multicolumn{3}{|c|}{ Pensions } & & \multicolumn{3}{|c|}{ Wages } & & \\
\hline & SNP & SPP & Total & & SNP & SPP & Total & & \\
\hline Mean & 566.2 & 827.2 & 775.9 & & 1003 & 1562.1 & 1446.4 & & \\
\hline Gini & 0.117 & 0.563 & 0.488 & & 0.397 & 0.507 & 0.496 & & \\
\hline $\mathrm{I}(\mathrm{e}=0.1)$ & 0.004 & 0.062 & 0.050 & & & & & & \\
\hline $\mathrm{I}(\mathrm{e}=0.5)$ & 0.018 & 0.270 & 0.215 & & & & & & \\
\hline $\mathrm{I}(\mathrm{e}=1.0)$ & 0.010 & 0.313 & 0.204 & & & & & & \\
\hline $\mathrm{I}(\mathrm{e}=2.0)$ & 0.057 & 0.696 & 0.634 & & & & & & \\
\hline $\mathrm{I}(\mathrm{e}=2.5)$ & 0.067 & 0.770 & 0.725 & & & & & & \\
\hline With Reform & $\alpha=1 \%$ & $\alpha=2 \%$ & $\alpha=3 \%$ & $\alpha=4 \%$ & $\begin{array}{c}\text { Pensio } \\
\alpha=5 \%\end{array}$ & $\alpha=6$ & $\alpha=7 \%$ & $\alpha=8 \%$ & $\alpha=9 \%$ \\
\hline Mean & 640.6 & 655.1 & 670.5 & 686.9 & 704.0 & 721.8 & 740.3 & 759.5 & 779.2 \\
\hline Gini & 0.351 & 0.361 & 0.371 & 0.380 & 0.390 & 0.398 & 0.406 & 0.414 & 0.421 \\
\hline $\mathrm{I}(\mathrm{e}=0.1)$ & 0.036 & 0.037 & 0.038 & 0.039 & 0.040 & 0.041 & 0.042 & 0.042 & 0.043 \\
\hline $\mathrm{I}(\mathrm{e}=0.5)$ & 0.156 & 0.159 & 0.163 & 0.166 & 0.170 & 0.173 & 0.177 & 0.180 & 0.183 \\
\hline $\mathrm{I}(\mathrm{e}=1.0)$ & 0.199 & 0.190 & 0.184 & 0.179 & 0.175 & 0.171 & 0.168 & 0.165 & 0.162 \\
\hline $\mathrm{I}(\mathrm{e}=2.0)$ & 0.659 & 0.621 & 0.600 & 0.588 & 0.580 & 0.575 & 0.571 & 0.569 & 0.568 \\
\hline $\mathrm{I}(\mathrm{e}=2.5)$ & 0.814 & 0.764 & 0.736 & 0.717 & 0.704 & 0.695 & 0.688 & 0.683 & 0.679 \\
\hline
\end{tabular}

Source: Author's simulation.

${ }^{21}$ Although also arbitrary, the social planner may use other reference points such as pick up a particular year of the simulation period or the very last year. At least, the average over the whole simulation period includes all the changes in pensions and inequality over a considerable period. 
It is interesting to note how different the two pension systems transmit inequality from labour life to retirement. For instance, in the SNP the Gini coefficient for wages drops from 0.40 to 0.12 ; this is simply explained by the system design on which the pension value must be within a minimum and maximum value. In contrast, in the SPP the wage inequality is transmitted to pensions, which is due to the individual capitalization scheme ${ }^{22}$.

The reform always reduces pension inequality when the distributional effect is analyzed with the Gini coefficient; and the inequality monotonically decreases as $\alpha$ lowers. The same results are observed for the Atkinson index until $e=0.5$. Higher values of aversion to inequality lead to changes in the ranking of pension distributions. The best distribution in the ranking is one that shows less inequality according to the planner's view. For this reason, a distribution may exhibit different positions for two planners that differ on their aversion to inequality. For example, a planner very averse to inequality $(e=2.5)$ prefers the scenario with a contribution rate $\alpha=9 \%$, while for a less averse planner ( $e=0.5$ ), the best scenario is that one with $\alpha=1 \%$.

It should be noted that the pension distribution with $\alpha=1 \%$, i.e. the maximum rate of contribution to the solidarity fund among all distributions, is at the worst position of the ranking when the planner is highly inequality averse. However, this result is not entirely unexpected. As the aversion to inequality increases, it gives more weight to the bottom of the pension distribution; therefore, a distribution more inequality distributed at the end of the scale would be worst ranked (Atkinson, 1970). At the bottom of the pension distribution there are insured who obtain a minimum pension and who obtain a pension below such value; for the latter the pension value is even lower when the contribution rate for individual capitalization is low. This in turn leads to greater inequality in the bottom of the distribution of pensions. This is precisely what we observe through the coefficient of variation calculated in each decile of the pension distributions of table 7. Looking at the bottom of the pension distributions, there is less variation among the pensions as $\alpha$ increases. It is also noticeable that the reform prevents many pensioners of receiving a pension below the minimum. Without implementing the reform, 30\% of the pensioners may receive a pension below the minimum; but such percentage might be only $2.8 \%$ if the reform were implemented.

${ }^{22}$ Without weighting pensions with the survival probability, the Gini coefficient for pensions in the SPP is 0.509, i.e. the transmission of inequality is almost perfect. 
Table 7

Coefficient of variation of pensions and \% of insured with minimum pension

\begin{tabular}{|c|c|c|c|c|c|c|c|c|c|c|c|c|}
\hline & \multicolumn{3}{|c|}{ No reform } & \multicolumn{9}{|c|}{ With reform } \\
\hline & SNP & SPP & Total & $\alpha=1 \%$ & $\alpha=2 \%$ & $\alpha=3 \%$ & $\alpha=4 \%$ & $\alpha=5 \%$ & $\alpha=6 \%$ & $\alpha=7 \%$ & $\alpha=8 \%$ & $\alpha=9 \%$ \\
\hline \multicolumn{13}{|c|}{ Coefficient of variation (x100): } \\
\hline Decile 1 (poorest) & 0.0 & 38.5 & 37.8 & 49.1 & 48.4 & 47.6 & 46.9 & 46.2 & 45.6 & 45.0 & 44.4 & 43.8 \\
\hline Decile 2 & 0.0 & 11.0 & 11.2 & 0.0 & 0.0 & 0.0 & 0.0 & 0.0 & 0.0 & 0.0 & 0.0 & 0.0 \\
\hline Decile 3 & 0.0 & 7.1 & 8.2 & 0.0 & 0.0 & 0.0 & 0.0 & 0.0 & 0.0 & 0.0 & 0.0 & 0.0 \\
\hline Decile 4 & 0.0 & 5.4 & 0.0 & 0.0 & 0.0 & 0.0 & 0.0 & 0.0 & 0.0 & 0.0 & 0.0 & 0.0 \\
\hline Decile 5 & 0.0 & 5.5 & 0.3 & 0.0 & 0.0 & 0.0 & 0.0 & 0.0 & 0.0 & 0.0 & 0.0 & 0.0 \\
\hline Decile 6 & 0.0 & 5.6 & 6.2 & 0.0 & 0.0 & 0.0 & 0.0 & 0.0 & 0.0 & 0.3 & 2.8 & 5.2 \\
\hline Decile 7 & 0.0 & 6.4 & 6.5 & 0.0 & 0.0 & 0.0 & 0.7 & 3.6 & 6.3 & 6.9 & 6.8 & 6.7 \\
\hline Decile 8 & 0.2 & 9.0 & 8.1 & 2.6 & 6.0 & 8.7 & 9.0 & 8.8 & 8.6 & 8.5 & 8.4 & 8.4 \\
\hline Decile 9 & 12.6 & 14.5 & 15.3 & 15.9 & 16.1 & 15.9 & 15.6 & 15.5 & 15.4 & 15.3 & 15.1 & 15.0 \\
\hline Decile 10 (richest) & 8.0 & 73.6 & 78.0 & 87.2 & 85.2 & 83.4 & 82.0 & 80.8 & 80.0 & 79.3 & 78.7 & 78.3 \\
\hline Total & 26.6 & 147.5 & 146.0 & 117.9 & 120.6 & 123.3 & 125.8 & 128.2 & 130.5 & 132.5 & 134.3 & 136.0 \\
\hline \multicolumn{13}{|c|}{ Percentage of insured with minimum pension: } \\
\hline$<$ min. pen. & 0.0 & 37.6 & 29.9 & 2.8 & 2.8 & 2.8 & 2.8 & 2.8 & 2.8 & 2.8 & 2.8 & 2.8 \\
\hline$=\min$. pen. & 79.6 & 3.6 & 19.2 & 74.5 & 71.9 & 69.0 & 65.9 & 62.7 & 59.5 & 56.3 & 53.1 & 50.1 \\
\hline
\end{tabular}

Likewise, the planner is able to rank the resulting pension distributions according to its welfare implications. As mentioned before, a SWF may be computed for each contribution rate $\alpha$. For instance, by using the Gini criterion the contribution rate $\alpha=9 \%$ offers the best effects on welfare; and as this rate decreases, the position of the WFS in the ranking decreases (see table 8). The SWF corresponding to the current scenario (without reform) is at the bottom of the ranking.

Table 8

Ranking of social welfare functions

\begin{tabular}{lcccccccccc}
\hline SWF & $\alpha=1 \%$ & $\alpha=2 \%$ & $\alpha=3 \%$ & $\alpha=4 \%$ & $\alpha=5 \%$ & $\alpha=6$ & $\alpha=7 \%$ & $\alpha=8 \%$ & $\alpha=9 \%$ & (No reform) \\
\hline Gini & 9 & 8 & 7 & 6 & 5 & 4 & 3 & 2 & 1 & 10 \\
$\mathrm{I}(\mathrm{e}=0.1)$ & 10 & 9 & 8 & 7 & 6 & 5 & 4 & 3 & 1 & 2 \\
$\mathrm{I}(\mathrm{e}=0.5)$ & 10 & 9 & 8 & 7 & 6 & 5 & 3 & 2 & 1 & 4 \\
$\mathrm{I}(\mathrm{e}=1.0)$ & 10 & 9 & 8 & 7 & 6 & 5 & 4 & 2 & 1 & 3 \\
$\mathrm{I}(\mathrm{e}=2.0)$ & 10 & 9 & 8 & 7 & 5 & 4 & 3 & 2 & 1 & 6 \\
$\mathrm{I}(\mathrm{e}=2.5)$ & 10 & 9 & 8 & 7 & 6 & 4 & 3 & 2 & 1 & 5 \\
\hline
\end{tabular}

Source: Author's simulation.

The ranking of the scenarios change slightly if the SWF are measured with the Atkinson criterion, except the current scenario that presents a rather different position to that found with the Gini criterion. Since the effect of average pension on the SWF is larger than the effect of greater inequality, the scenario of no reform is not ranked too badly. As mentioned before, the planner dislikes inequality at the bottom of the distribution in the Atkinson index, thus lower values of $\alpha$ may be less preferred.

Overall, there are important consequences of the reform on the pension debt, pension inequality and welfare. It is worth to present these effects all together in order to observe tradeoffs for policy-making. 
Figure 2

\section{Debt reduction, inequality and welfare (Gini criterion)}

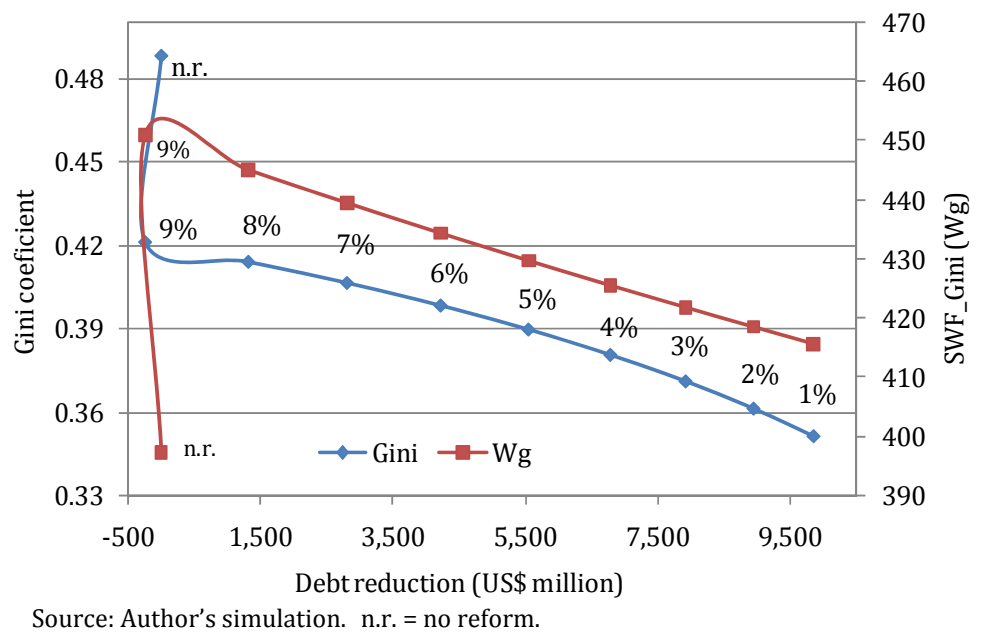

Figure 2 shows the effects of reform on pension debt, inequality and welfare according to the Gini criterion. As noted, any scenario of reform involves improvement in welfare and equity with respect to the current situation. If the planner is only interested in the effects on welfare, then he chooses the contribution rate $\alpha=9 \%$, given that this scenario offers the highest level of welfare. However, this scenario increases the pension debt by US\$245 million. In contrast, a planner more concerned with achieving greater savings in the pension debt will choose a lower rate of contribution to the individual account, which will reduce inequality in pensions as well. Finally, if the criterion for choosing a scenario is to keep pensioners as well off as they would be with no reform, then the contribution rate $\alpha$ should be only $1 \%$, which in turn implies the largest save of debt and the more equal pension distribution.

These results change when using the Atkinson criterion. According to the left panel of figure 3 (with $e=0.5$ ), the planner favours a contribution rate $\alpha$ slightly lower than $7 \%$ as this rate ensures at least the same welfare that would be there with no reform. Furthermore, it saves US $\$ 2,800$ million and reduces inequality. Similarly, in the right panel (with $e=2.5$ ) the $\alpha$ preferred by the planner is between $5 \%$ and $6 \%$, it generates savings between US\$4,200 and US\$5,500 million and also reduces inequality. However, if the first goal of the planner is to reduce inequality, then he prefers a contribution rate of $\alpha=9$. 
Figure 3

Debt reduction, inequality and welfare (Atkinson criterion)
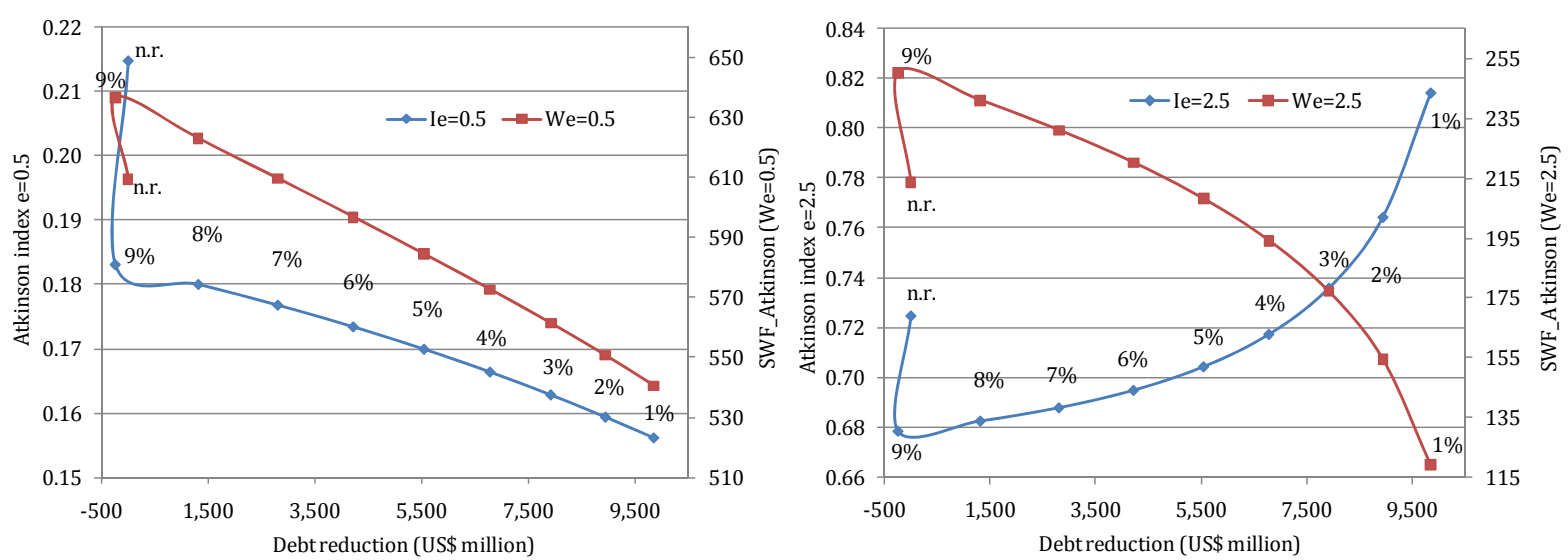

Source: Author's simulation. n.r. = no reform.

In summary, there are several effects of the reform proposal and its relative importance depends on the planner's view. The trade-offs shown in this section, rather than serve as a manual for making a decision on the best possible scenario for reform, are useful to instruct and highlight the different policy objectives and their interplay.

\subsection{A marginal contribution rate}

While the reform proposal recovers the principle of solidarity in the pension system, it is still possible to consider additional measures to ensure greater transfers from high-income to low income insured, and in turn reduce pension debt. It is instructive to study the effect of an marginal contribution paid by those insured who earn above a threshold amount. We present two different possible schemes:

i) The contribution rate to the solidarity fund is $\beta$ for $Y_{i k} \leq Y_{m}$ and $\beta+t_{1}$ for $Y_{i k}-Y_{m}$, given $Y_{i k}>Y_{m}$.

The contribution rate to the individual account is $\alpha$, applied to total wage. It still holds that $\alpha+\beta=10 \%$.

ii) The contribution rate to the solidarity fund is $\beta$ for $Y_{i k} \leq Y_{m}$ and $\beta+\alpha t_{2}$ for $Y_{i k}-Y_{m}$, given $Y_{i k}>Y_{m}$.

The contribution rate to the individual account is $\alpha$ for $Y_{i k} \leq Y_{m}$ and $\alpha\left(1-t_{2}\right)$ for $Y_{i k}-Y_{m}$, given $\mathrm{Y}_{\mathrm{ik}}>\mathrm{Y}_{\mathrm{m}}$. It still holds that $\alpha+\beta=10 \%$.

In the first scheme, the base rate of contribution (to individual account and solidarity fund) is $10 \%$; only those members who earn more than threshold $Y_{m}$ contribute more to the solidarity fund. So, a majority of insured contributes $10 \%$ while only those placed at the top of income distribution contribute $10 \%+\mathrm{t}_{1}\left(1-\mathrm{Y}_{\mathrm{m}} / \mathrm{Y}_{\mathrm{ik}}\right)$. On the other hand, if the second scheme were applied, the contribution rate of $10 \%$ would be common to all insured, although the allocation between the individual account and solidarity fund will depend on the income distribution position. 
Table 9 shows the effects on pension debt of applying marginal contributions when $Y_{m}$ is $\mathrm{S} / .60,000$ per year, $\mathrm{t}_{1}=2 \%$ and $\mathrm{t}_{2}=25 \%^{23}$. Although these values are rather arbitrary, they are still instructive to assess the effectiveness of applying marginal contributions to reduce the pension debt.

\section{Table 9}

\section{Pension debt with marginal contribution (US\$ million)}

\begin{tabular}{|c|c|c|c|c|c|c|c|c|c|}
\hline \multicolumn{10}{|l|}{ No Reform } \\
\hline a. Net Reserve & 10,296 & & & & & & & & \\
\hline With Reform & \multicolumn{9}{|c|}{ Contribution rate to individual account } \\
\hline \multicolumn{10}{|l|}{ i) With marginal contribution $t_{1}=2 \%$} \\
\hline b. Present value of contributions & 20,763 & 18,456 & 16,149 & 13,842 & 11,535 & 9,228 & 6,921 & 4,614 & 2,307 \\
\hline c. Present value of marg. contr. & 712 & 712 & 712 & 712 & 712 & 712 & 712 & 712 & 712 \\
\hline f. Savings: a-e & 10,567 & 9,661 & 8,635 & 7,496 & 6,259 & 4,931 & 3,517 & 2,027 & 467 \\
\hline \multicolumn{10}{|l|}{ ii) With marginal contribution $t_{2}=25 \%$} \\
\hline g. Present value of contributions & 20,763 & 18,456 & 16,149 & 13,842 & 11,535 & 9,228 & 6,921 & 4,614 & 2,307 \\
\hline h Present value of marg. contr. & 89 & 178 & 267 & 356 & 445 & 534 & 623 & 712 & 801 \\
\hline i. Reserve for insured & 21,212 & 19,811 & 18,529 & 17,360 & 16,290 & 15,311 & 14,418 & 13,600 & 12,852 \\
\hline
\end{tabular}

If the first scheme were implemented, the marginal contribution might increase the present value of contributions in US\$712, which in turn leads to an additional reduction of the same amount in the pension debt. This saving is relatively less important when the contribution rate $\alpha$ is lower, which suggests that the choice of a high value of $\alpha$ should include the implementation of a marginal contribution in order to obtain significant effects in reducing the pension debt. Similarly, the savings achieved with the second scheme gains significance when $\alpha$ is greater. However, the present value of marginal contribution is not fixed as in the first scheme, but it is increasing with $\alpha$. Overall, the first scheme may achieve greater savings than the second one, though only up to $\alpha=8 \%$.

Individuals who earn more than $Y_{m}$ may prefer the second scheme because the amount contributed to the solidarity fund comes from the resources that had been contributed to the individual account anyway $\left(\alpha \mathrm{t}_{2}\left(\mathrm{Y}_{\mathrm{ik}}-\mathrm{Y}_{\mathrm{m}}\right)\right)$, which does not affect the disposable income. Since resources of the individual account can be annuitized only at retirement and that disposable income can be spent immediately or invested in other forms of savings, it is clear that the insured would prefer the scheme that offers more disposable income ${ }^{24}$.

Given that marginal contribution is only applied to insured in the top of income distribution, the advantage of the first scheme is that it provides a clearer mechanism of solidarity from highincome to low-income insured. In any case, if the implementation of a marginal contribution

${ }^{23}$ Insured earning more the $\mathrm{S} / 60,000$ a year belong to top $5 \%$ of wage distribution.

${ }^{24}$ Note that the probability of voluntary enrolment in the Peruvian pension system is very low (Li \& Olivera, 2009). 
were strongly resisted, the multi-pillar system itself offers significant reduction of the pension debt (see figure 4) and improvements in welfare and inequality.

\section{Figure 4 \\ Pension debt reduction with and without marginal contribution}

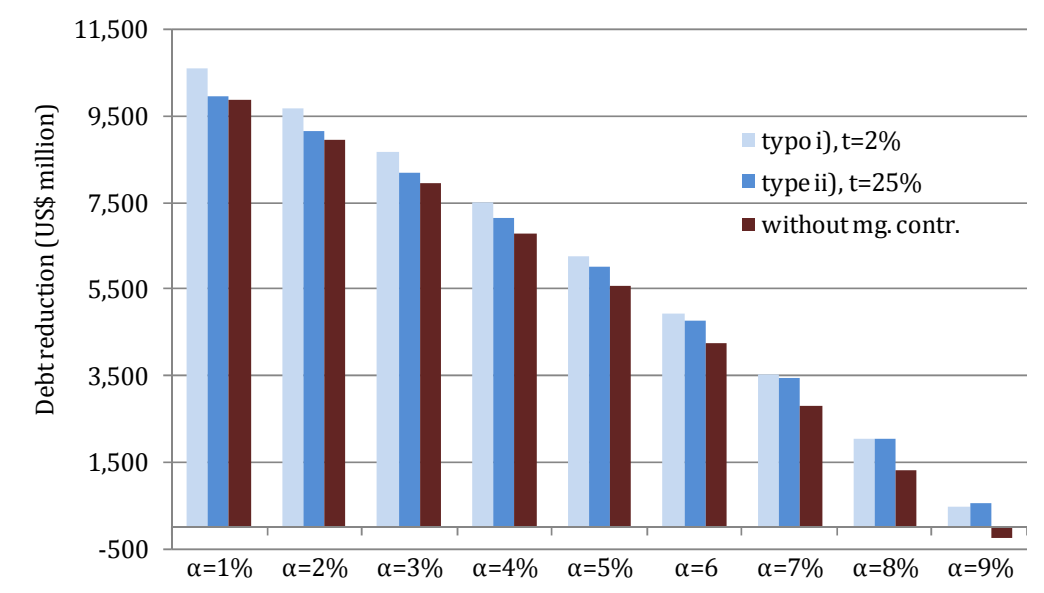

Source: Author's simulation.

The first scheme does not change inequality and welfare indexes as these are calculated with pension, which values are not affected by the marginal contribution. In comparison to a reform without marginal contribution, the second scheme produces a very slight reduction in inequality according to Gini coefficient and Atkinson index (when e $\leq 0.5$ ), and less welfare whether using Gini coefficient or Atkinson index 2526.

\subsection{The third pillar}

So far the reform analysis has focused on the effects of first and second pillar as these are mandatory and are the basis on which the new pension system is sustained. The third pillar is voluntary and is intended for workers willing to save more in order to obtain better pensions. In general, low-income individuals might not be interested in this scheme because they must allocate its limited resources on more immediate needs. The third pillar should be designed to alleviate rigidities of first and second pillar (Holzmann et al, 2005). This may attract individuals who are already enrolled in the pension system, and even those who are not insured (e.g. professional self-employed workers) and willing to participate if incentives are adequate in their view.

\footnotetext{
25 The reason is that the effect of reducing the average pension (pensions of high-income insured) dominates any improvement in inequality. Therefore, the first scheme might be preferred to the second one according to its best results in welfare.

${ }^{26}$ Just to be provocative, we simulate the effect on the SPP if this is transformed into a system with the same rules of the SNP, which means a reversal of the 1993 pension reform (the detailed exercise is available at request). The SPP may reach a surplus of US $\$ 4,501$ million, which could be used to alleviate part of the imbalance in the SNP. Argentina is the only Latin American country that has fully reversed its pension reform (in October 2008).
} 
A possible scheme is fixing a wage ceiling to charge the AFP's administrative fee (recall that the fee is a fixed percentage of the insured's monthly salary). So, insured that earn more than that ceiling and choose the third pillar will pay the fee only up to the ceiling. In addition, the AFP may establish other fee schema for those who earn less than the ceiling or who are not enrolled in the pension system. It is expected to find resistance in the AFP as the main portion of its revenues relies on the fees charged to high-income insured. But it is also true that the proposed reform would increase significantly the number of its contributors (those coming from SNP) and revenues. In December 2006, there were 1.4 and 0.57 million contributors in the SPP and SNP respectively; which means that, at the reform date, the number of AFP contributors would rise by $40 \%$. This increase contrasts sharply with the yearly growth rate of the number of contributors noticed until December 2006, which was only $8.2 \%$. Furthermore, if the same administrative fee charged previous reform (in average this is $1.8075 \%$ of wages) is kept, the multi-pillar system would allow the AFP to increase its revenues by $23 \%$, which is larger than the yearly growth rate of AFP revenues (8.1\% between Dec-1997 and Dec-2006). Table 10 shows potential gains for the AFP.

Table 10

Administrative fee Revenues (S/. thousands, Dec-2006)

\begin{tabular}{|c|c|c|}
\hline Concept & & \\
\hline \multicolumn{3}{|l|}{ SNP } \\
\hline Number of contributors & 568,847 & \\
\hline Gross collection & 837,906 & \\
\hline \multicolumn{3}{|l|}{$S P P$} \\
\hline Number of contributors & $1,412,001$ & \\
\hline Administrative fee revenues & 505,695 & \\
\hline \multicolumn{3}{|l|}{ With Reform } \\
\hline Number of contributors & $1,980,848$ & \\
\hline Administrative fee revenues from SNP & 116,501 & \\
\hline Administrative fee revenues from SPP & 505,695 & \\
\hline Total administrative fee revenues & 622,196 & \\
\hline \multicolumn{3}{|l|}{ With reform and third pillar } \\
\hline Variation in total administrative fee revenues & mg. rate $=0 \%$ : & mg. rate $=0.9 \%$ : \\
\hline Wage ceiling: $S / .6,000$ & $-38,124$ & 39,189 \\
\hline Wage ceiling: $S / .7,000$ & $-17,889$ & 49,306 \\
\hline Wage ceiling: S/. 8,000 & $-1,860$ & 57,320 \\
\hline Wage ceiling: $S / .9,000$ & 10,479 & 63,490 \\
\hline Wage ceiling: $S / .10,000$ & 20,994 & 68,748 \\
\hline
\end{tabular}

Implementing the reform without the third pillar, AFP's revenues would increase automatically by S/.116.5 million, but a wage ceiling of S/.6,000 a month would reduce revenues by 38 million (first column of table 10). As wage ceiling rises, AFP find positive variation in its total revenues. For instance, a ceiling of S/.10,000 would increase revenues by S/.21 million. The second column of table 10 shows the variation on AFP's revenues if the fee scheme of the third pillar is varied slightly. Instead of charging no fee beyond wage ceiling, the 
AFP can charge half the fee, i.e. $0.90375 \%$. By this way, the revenues are reduced less than in the first fee scheme. For example, a ceiling of S/.10,000 would raise revenues by S/.68.7 million.

Although the arrival of insured from the SNP increases AFP's administrative costs, this increase should not be directly proportional to the number of new insured due to the existence of economies of scale in the pension fund industry ${ }^{27}$. Therefore, it is feasible to set a fee schedule for the third pillar without an increase of fees. In addition, the third pillar would be open to nonenrolled workers and insured who earn less than the ceiling, which would allow AFP to collect extra fees and revenues. The setting of this fee may also serve as an additional vehicle for competition among AFP.

On the other hand, the AFP would no longer have a system competitor (the SNP) for recruiting new workers, which ensures a better and broader base of contributors. Moreover, the AFP are very profitable firms that already recovered their initial investment as is seen in their high profits and large levels of Return on Equity obtained during last years, even higher than in other Latin American pension systems (World Bank, 2004). Among Peruvian industries, the AFP industry is the sector with best returns (Gerens, 2006).

\section{Concluding remarks}

The multi-pillar system proposed enables to reinstate the principle of solidarity in the Peruvian pension system. Peruvian workers are not unfamiliar to this social security principle. The pension system that prevailed before the establishment of individual capitalization was the SNP, a system that includes, by design, the principle of solidarity. Moreover, the insured of the SPP contributed, until 1995, 1\% of their wages as a solidarity contribution to IPSS (Peruvian Institute of Social Security), which was the predecessor of SNP.

As is clear from our proposal, solidarity is a valued characteristic in social security in general, and particularly in a pension system. Furthermore, the recovery of this principle allows us to use the pension system as an additional tool for income redistribution.

It is worth to mention that a multi-pillar system may diversify risks better. The factors that affect labour variables and hence the first pillar are not perfectly correlated with factors that affect financial variables, which in turn determine the pension funds performance in the second pillar (Holzman et al, 2005; Lindbeck and Persson, 2003).

The proposal has three important effects. First, pension inequality is notably reduced, which breaks the transmission of inequality from labour income to pensions. Second, the reform is welfare enhancing, although it depends on the value of the contribution rate chosen for the individual account. And in third place, pension debt is importantly reduced. The key aspect of

27 Galarza and Olivera (2001) and Moron and Carranza (2004) show evidence of economies of scale in the Peruvian pension fund industry. 
our results is that the proposed reform shows improvements in all these three issues. However, we acknowledge the existence of possible behavioural adjustments (e.g. in the labour market) that are not accounted for in our simulation results, due to data limitations.

As minimum pensions are financed by contributions from insured rather than transfers from the Treasury, the State would allocate these freed resources to other social programs, which enhances the social spending. Furthermore, the implementation of a minimum pension scheme gives the same rights to all insured whether these come from SPP or SNP. The proposed third pillar may attract high-income insured and workers who are not obligated to enrol in the pension system due to rigidities of the first and second pillar. It is expected that AFP will not increase their fees due to the existence of economies of scale in the pension fund industry and the fact that the SNP will no longer be a competitor. Indeed, the creation of a third pillar is another mean for promoting competition among AFP. For these reasons, the reform proposal may also be thought of as an opportunity to bring down administrative fees.

Organizational aspects of the reform are beyond the scope of our proposal but may have interesting effects. For example, insured of the SNP could choose any AFP or could be "assigned", by any criterion, to each of these firms. In the first case, firms would compete for those insured (over 600 thousand contributors in the SNP at Dec-2007); although instead of competing via fees reductions, they could compete via advertising, sellers or gifts, which increase administrative expenses. The second case prevents the increase of administrative costs but does not ensure the reduction of fees. Another option is to offer the entire group of SNP insured to a new AFP through a tender (choosing the offer with the lowest fee). Some companies might be interested in this scheme as they can avoid the high sunk costs of starting business, that are typical in the pension funds industry. In turn, this fee should be lower than that of the rest of AFP and influence them to bring down their own fees. We do not address the design characteristics of the tender, but this should minimally include clauses of temporal loyalty for the SNP insured and the commitment not to raise the fee agreed for a certain period. Although politically risky and controversial, the State might create a governmental AFP with the automatic inclusion of all insured from the SNP; and its management and regulation would be identical to those of the AFP. In this case, the fee charged by the Government might work as a mechanism to reduce fees of the other AFP.

Undoubtedly, the reform proposal opens up many possibilities to improve the pension system in areas not considered in the proposal itself, particularly in the fee charged by the AFP. In this sense, another form to organize the reform might just be the negotiation between the AFP and the State with the aim to reduce the fee in exchange for the insured of the SNP. There is no analysis on the characteristics of the solidarity fund, but it may be administrated by the AFP 
or other private firms specialized in funds management. Again, a tender offer for this fund could enhance conditions for its administration.

\section{References}

Arenas de Mesa and Mesa Lago (2006), "The Structural Pension Reform in Chile: Effects, Comparisons with other Latin American Reforms, and Lessons", Oxford Review of Economic Policy, Vol. 22, No.1, pp.149-167.

Arenas de Mesa, A., D. Bravo; J. Behrman; O. Mitchell and P. Todd (2008), "The Chilean Pension Turns 25: Lessons from the Social Protection Survey". In: S. Kay and T. Sinha (eds.), Lessons from Pension Reform in the Americas. New York: Oxford University Press. 2008.

Arza, Camila (2008), "Pension Reform in Latin America: Distributional Principles, Inequalities and Alternative Policy Options", Journal of Latin American Studies, 40: 1-28.

Atkinson, A.B. (1970), "On the measurement of inequality", Journal of Economic Theory Vol. 2, pp. 244-63.

Barr, N. and P. Diamond (2009), "Reforming pensions: Principles, analytical errors and policy directions", International Social Security Review Vol. 62(2): 5-29.

Barr, A. and T. Packard (2005), "Seeking solutions to Vulnerability in Old Age: Preferences, constraints, and alternatives for coverage under Peru's pension system" The Centre for the Study of African Economies Working Paper Series, $\mathrm{N}^{\circ} 239$.

Bernal, N., Muñoz, A., Perea, H., Tejada, J. y Tuesta, D. (2008), “Una mirada al Sistema Peruano de Pensiones. Diagnóstico y Propuestas". Grupo BBVA. Editorial Norma.

Bertranou, F. and A. Sánchez (2003), "Características y determinantes de la densidad de aportes a la seguridad social en la Argentina 1994-2001," in "Historias Laborales en la Seguridad Social", Serie de publicaciones de la Secretaría de Seguridad Social, Año I, №1, Ministerio de Trabajo, Empleo y Seguridad Social, Argentina..

Galarza, B. y J. Olivera (2001), "La Industria del Sistema Privado de Pensiones en el Perú", SBS Documentos de Trabajo No. 02/2001. Superintendencia de Banca y Seguros.

Gasparini, L., G. Cruces, L. Tornarolli and M. Marchionni (2009), "A Turning Point? Recent Developments on Inequality in Latin America and the Caribbean", CEDLAS, working paper No. 81.

Gerens (2006), "Estudio competitividad internacional y rentabilidad de las empresas en el Perú". Lima, Perú.

Holzman, R.; Palacios, R. and Zviniene, A. (2004) "Implicit Pension Debt: Issues, Measurement and Scope in Internacional Perspective", Social Protection Discussion Paper Series No. 0403, World Bank.

Holzmann, R., R. Hinz and staff of the World Bank (2005), “Old-Age Income Support in the 21st Century: An International Perspective on Pension Systems and Reform", Washington: World Bank. 2005.

ILO (2009), "2008 Labour overview. Latin America and The Caribbean", International Labour Office, Regional Office for Latin America and the Caribbean. Lima.

Lambert, P.J. (2001), "The Distribution and Redistribution of Income”, 3rd Edition, Manchester: Manchester University Press. 2001.

Lambert, P.J., D. Millimet and D.J. Slottje (2008) "Inequality Aversion, Income Inequality, and Social Policy in the US: 1947 - 1998," in G. Betti and A. Lemmi (eds.), Advances on Income Inequality and Concentration Measures: Collected Papers in Memory of Corrado Gini and Max O. Lorenz. New York: Routledge Publisher. 2008.

Lindbeck, A. and M. Persson (2003), "The Gains from Pension Reform", Journal of Economic Literature, Vol. 41(1): 74-112.

Li, C. and J. Olivera (2009) "Voluntary Enrolment in the Peruvian Private Pension System", International Social Security Review, forthcoming, September 2009. 
MEF (2007), "Informe anual de deuda pública 2007", Ministerio de Economía y Finanzas. Dirección Nacional de Endeudamiento Público.

MEF (2008), "Informe final de la comisión técnica (Ley 28991 DS 051-2007-EF). Plan de mejoras al SNP y SPP que permitan asegurar su coexistencia en el mediano y largo plazo y propuesta de nueva política de inversiones del FCR".

Morón, E. y E. Carranza (2003), "Diez años del Sistema Privado de Pensiones: avances, retos y reformas", Universidad del Pacifico.

Morón, E. y E. Carranza (2004), "Teoría de Mercados Oligopólicos y Economías de Escala: Lecciones para el caso de las AFP". CIUP, Lima.

Titelman, Daniel y Andras Uthoff, (2003), "Incertidumbre económica, seguros sociales, solidaridad y responsabilidad fiscal", Serie Financiamiento del Desarrollo, 134. CEPAL.

World Bank (1994), "Averting the Old-Age Crisis: Policies to Protect the Old and Promote Growth", New York: Oxford University Press. 1994

World Bank (2004), "Peru: Restoring the Multiple Pillars of Old Age Income Security", Human Development Department, Report $\mathrm{N}^{\circ} 27618$-PE.

Zvinieni, A and T. Packard (2002), "A Simulation of Social Security Reforms in Latin America: What Has Been Gained?". Background Paper for Regional Study on Social Security Reform, Office of the Chief Economist, Latin America and Caribbean Regional Office, World Bank. 


\section{Appendix}

\section{Computation of pensions}

The pensions in the SNP are computed according to pension rules stated in norms Ley 27617 and DS 099-2002-EF. The SNP offers 14 pensions per year, but due to comparability reasons with the SPP and the reform proposed, we recalculate those pensions in order to consider only 12 pensions per year. The subscripts $i$ and $k$ included in the variables refer to a particular individual and his age at December 2006, respectively. $k_{s n p}$ and $k_{s p p}$ indicate the age at which the individual enrolled in the corresponding pension system. The next expression calculates the number of contributions and pensions in the SNP:

$$
\begin{aligned}
& \tilde{A}_{i k}^{s n p}=t_{0}^{s n p}\left(k-k_{s n p}\right)+t_{1}^{s n p}(65-k) \\
& A_{i k}^{s n p}=\left\{\begin{array}{l}
\tilde{A}_{i k}^{s n p} \text { if } \quad \tilde{A}_{i k}^{s n p} \geq 20 \\
20 \text { if } \quad \tilde{A}_{i k}^{s n p}<20 \quad \& \quad 65-k_{s n p} \geq 20 \\
\tilde{A}_{i k}^{s n p} \text { if } \quad \tilde{A}_{i k}^{s n p}<20 \quad \& \quad 65-k_{s n p}<20
\end{array}\right.
\end{aligned}
$$

where:

$A_{i k}^{\text {snp }}$ : Number of contributed years between $k_{s n p}$ and 65 (the retirement age).

$t_{0}^{\text {snp }}$ : Density of contributions between $k_{s n p}$ and $k$.

$t_{1}^{\text {snp }}$ : Density of contribution between $k$ and 65 .

The values for the densities of contributions must be between $0 \%$ and $100 \%$. The above equations imply that the insured will contribute for at least 20 years. The reason for this is that such period is the minimum amount of years needed to be entitled a minimum pension. Therefore, the insured will find ways to fulfil this requisite, otherwise he will not obtain a pension. The SNP pension is computed as:

$$
\begin{aligned}
& P_{i k}^{s n p}=\left[T R B_{i k}+0.02\left(A_{i k}^{s n p}-20\right) S_{s n p}\right] Y_{i k} \\
& \text { with } \quad T R B_{i k}+0.02\left(A_{i k}^{s n p}-20\right) S_{s n p} \leq 1 \quad \& \quad P_{i k}^{s n p} \in\left[P_{\min }^{s n}, P_{\max }^{s n p}\right]
\end{aligned}
$$

where:

$P_{i k}^{s n p} \quad$ : Retirement pension for individual $i$ and age $k$.

$T R B_{i k}$ :Basic replacement rate, which depends on the insured's cohort. For those insured born until 1947, the $T R B_{i k}$ is $50 \%$. Between 1948 and 1952, it is 45\%; between 1953 and 1962 , it is $40 \%$, between 1963 and 1972, it is 35\%; and since 1973, it is $30 \%$.

$S_{\text {snp }}$ : It takes value 1 if $A_{i k}^{\text {snp }}-20>0$ and zero otherwise.

$Y_{i k} \quad$ : Wage of individual $i$ and age $k$.

$P_{\min }^{s n p} \quad$ : Minimum pension in the SNP.

$P_{\max }^{s n p} \quad$ : Maximum pension in the SNP.

The density of contributions that will be used later to compute the actuarial reserve, is obtained from the next expression:

$$
d_{i k}^{s n p}=\frac{A_{i k}^{s n p}}{65-k_{s n p}}
$$


In contrast with the SNP's pension computation process, in the SPP the computation follows a simple capitalization process (we assume monthly capitalization):

$$
P_{i k}^{s p p}=\frac{\frac{14}{12} Y_{i k} \times 10 \% \times d_{i k}^{s p p} \frac{\left[(1+\tilde{r})^{65-k}-1\right]}{(1+\tilde{r})^{1 / 12}-1}+C I C_{0}(1+\tilde{r})^{65-k}+B R_{i k}}{C R U_{65, y}}
$$

where:

$C_{0} \quad$ : Existing balance in the individual capitalization account (at December 2006).

$B R_{i k} \quad$ : Recognition bond, at December 2006 value.

$\tilde{r} \quad$ : Pension fund yearly return rate.

$C R U_{65, y}$ : Annuity price at retirement age, including a spouse of $y$ years old.

In the SPP it is also necessary to estimate the number of contributions paid by the insured in order to assess the entitlement of a minimum pension and to build the density of contributions. An insured of the SPP will receive a minimum pension if he was previously enrolled in the SNP and -before the creation date of the SPP- and contributed at least 20 years to any of both systems. Information on the number of years contributed to the SNP is unavailable; therefore it is assumed that this is equal to the number of years recorded in the BR, which indicates the years of contribution officially recognized by the ONP.

$$
\begin{aligned}
& \tilde{A}_{i k}^{s p p}=A_{i k}^{B R}+t_{0}^{s p p}\left(k-k_{s p p}\right)+t_{1}^{s p p}(65-k) \\
& A_{i k}^{s p p}=\left\{\begin{array}{l}
\tilde{A}_{i k}^{s p p} \text { if } \quad \tilde{A}_{i k}^{s p p} \geq 20 \\
20 \text { if } \quad \tilde{A}_{i k}^{s p p}<20 \quad \& \quad 65-k_{s p p} \geq 20 \\
\tilde{A}_{i k}^{s p} \quad \text { if } \quad \tilde{A}_{i k}^{s p p}<20 \quad \& \quad 65-k_{s p p}<20
\end{array}\right.
\end{aligned}
$$

where:

$A_{i k}^{s p p}$ : Number of years contributed to the SNP and SPP until age 65.

$A_{i k}^{B R}:$ Number of years contributed to the SNP recorded in BR.

$t_{0}^{s p p}$ : Density of contributions between $k_{s p p}$ and age $k$.

$t_{1}^{s p p}$ : Density of contributions between age $k$ and 65 .

Therefore, the density of contributions used to compute pensions in the SPP is:

$$
d_{i k}^{s p p}=\frac{A_{i k}^{s p p}-A_{i k}^{B R}}{65-k_{s p p}}
$$

The calculation of the annuity price implies the use of survival probability computed from a mortality table and a discount rate. The formula is as follows:

$$
\begin{aligned}
& C R U_{65}=12\left(\sum_{j=0}^{M-65} \frac{p_{65,65+j}}{(1+\hat{r})^{j}}-\frac{11}{24}\right) \\
& C R U_{65, y}=C R U_{65}+12 \theta_{\text {spp }}\left(\sum_{i=0}^{M-y} \frac{q_{y, y+i}\left(1-p_{65,65+i}\right)}{(1+\hat{r})^{i}}\right)
\end{aligned}
$$


where:

$p_{65,65+j}$ : Probability of survival from age 65 to $65+j$.

$M \quad$ : Maximum survival age according to mortality table.

$\hat{r} \quad$ : Annuity discount rate.

$\theta_{s p p} \quad$ : Percentage of the husband's pension that the widow will receive.

$q_{y, y+i}$ : Probability of survival from age $y$ to age $y+i$ for the widow.

Equation 10 might be used for a single insured, while equation 11 is used for a married insured. The $\theta_{s p p}$ is determined by regulation, but it is still possible that insured chose another value if he contracts a complementary product instead of a default life annuity. As explained in the proposal, the minimum pension in the multi-pillar system is entitled only to those insured that contributed for at least 20 years to SNP and/or SPP:

$$
\begin{aligned}
& \tilde{A}_{i k}^{\text {mix }}=A_{i k}^{B R}+t_{0}^{\text {sis }}\left(k-k_{\text {sis }}\right)+t_{1}^{\text {mix }}(65-k) \\
& A_{i k}^{m i x}=\left\{\begin{array}{l}
\tilde{A}_{i k}^{m i x} \text { if } \tilde{A}_{i k}^{m i x} \geq 20 \\
20 \text { if } \tilde{A}_{i k}^{m i x}<20 \quad \& \quad 65-k_{s i s} \geq 20 \\
\tilde{A}_{i k}^{m i x} \text { if } \tilde{A}_{i k}^{\text {mix }}<20 \quad \& \quad 65-k_{s i s}<20
\end{array}\right.
\end{aligned}
$$

Where:

$A_{i k}^{\text {mix }}:$ Number of years contributed to the mixed system (SNP and SPP included) up to age 65.

$t_{0}^{s i s}$ : Density of contributions between $k_{s i s}$ and age $k$. sis = snp, spp.

$t_{1}^{m i x}$ : Density of contributions between current age and age 65.

Thus, the pension in the mixed system is computed as:

$$
\begin{aligned}
& P c_{i k}^{\text {mix }}=\frac{\frac{14}{12} Y_{i k} \times a \times d_{i k}^{\text {mix }} \frac{\left[(1+\tilde{r})^{65-k}-1\right]}{(1+\tilde{r})^{1 / 12}-1}+C I C_{0}(1+\tilde{r})^{65-k}+B R_{i k}}{C R U_{65, y}} \\
& P_{i k}^{\text {mix }}=\left\{\begin{array}{lll}
P c_{i k}^{\text {mix }} & \text { if } \quad P c_{i k}^{\text {mix }}>P_{\text {min }}^{\text {mix }} \\
P_{\text {min }}^{\text {mix }} & \text { if } \quad P c_{i k}^{\text {mix }} \leq P_{\operatorname{mix}}^{\text {mix }} \quad \& \quad A_{i k}^{\text {mix }} \geq 20 \\
P c_{i k}^{\text {mix }} & \text { if } \quad P c_{i k}^{\text {mix }} \leq P_{\text {min }}^{\text {mix }} \quad \& \quad A_{i k}^{\text {mix }}<20
\end{array}\right. \\
& d_{i k}^{\text {mix }}=\frac{A_{i k}^{\text {mix }}-A_{i k}^{B R}}{65-k_{s i s}}
\end{aligned}
$$

$P_{i k}^{m i x}$ indicates the final value of the pension in the multi-pillar system.

\section{Simulation of the actuarial reserve}

\section{i. Actuarial reserve for insured of the SNP:}

For insured $\leq 65$ years old:

$$
R A_{i k}^{s n p}=P_{i k}^{s n p} \times C R U_{65, y}
$$




$$
\begin{aligned}
& R A_{k}^{\text {snp }}=p_{k, 65} \times \sum_{i=1}^{N_{k}} R A_{i k}^{\text {snp }} \\
& R A_{\leq 65}^{\text {snp }}=\sum_{k=21}^{65} R A_{k}^{\text {snp }}(1+r)^{k-65} \\
& R A_{\text {sob }, k}^{\text {snp }}=\sum_{j=1}^{65-k} C R U_{k}^{s o b}\left(1-p_{k, k+j}\right)\left(P_{s o b}^{\text {snp }} \hat{N}_{k}+\theta_{s n p} \hat{S}_{k}\right)(1+r)^{-j} \\
& R A_{\text {sob }}^{\text {snp }}=\sum_{k=21}^{64} R A_{s o b, k}^{\text {snp }}
\end{aligned}
$$

For insured $>65$ years old:

$$
\begin{aligned}
& R A_{i k}^{s n p}=P_{i k}^{s n p} \times C R U_{k, y} \\
& R A_{k}^{s n p}=\sum_{i=1}^{N_{k}} R A_{i k}^{s n p} \\
& R A_{>65}^{s n p}=\sum_{k=66}^{T} R A_{k}^{s n p}
\end{aligned}
$$

And total actuarial reserve for insured is:

$$
R A_{\text {snp }}=R A_{\leq 65}^{s n p}+R A_{s o b}^{s n p}+R A_{>65}^{s n p}
$$

where:

$R A_{i k}^{\text {snp }}$ : Actuarial reserve for an individual i of age $k$.

$R A_{k}^{\text {snp }} \quad$ : Actuarial reserve for all individuals of age $k$.

$N_{k} \quad$ : Number of individuals of age $k$ in the sample.

$R A_{\leq 65}^{s n p}:$ Actuarial reserve for all individuals of age $k \leq 65$.

$r \quad:$ Discount rate.

$R A_{s o b, k}^{s n p}:$ Actuarial reserve for survivors of pension holders of age $k$ that die before 65 .

$C R U_{k}^{s o b}$ : Annuity price for previously mentioned survivors.

$P_{\text {sob }}^{\text {snp }} \quad$ : Minimum pension received by previously mentioned survivors.

$\hat{N}_{k} \quad$ : Number of individuals of age $k$, with $P_{i k}^{\text {snp }}<P_{\text {sob }} / \theta_{\text {snp }}$.

$\hat{S}_{k} \quad$ : Sum of pensions of individuals of age $k$, with $P_{i k}^{s n p} \geq P_{\text {sob }} / \theta_{\text {snp }}$.

$R A_{\text {sob }}^{\text {snp }}$ : Actuarial reserve for survivors of pension holders that die before 65 .

The formula used for the annuity price in the SNP differs slightly from SPP's. In the SNP, the monthly payment is overdue (at the end of the month and not at the beginning as in the SPP), there are two additional pensions paid each in July and December, and the percentage of pension received by beneficiaries are different. Finally, it is assumed that individuals older than 65 retire immediately (according to equations 22-24).

\section{ii. Actuarial reserve for insured of the SPP:}


Differently from the reserve estimated for the SNP and published by the ONP, there is no official publication on future payments of minimum pensions in the SPP. However, it is necessary to quantify these reserves in order to compare with the estimated costs of reform.

For insured $\leq 65$ years old:

$$
\begin{aligned}
& R A_{i k}^{s p p}=S_{\min }^{s p p} \times\left(P_{\min }^{s p p}-P_{i k}^{s p p}\right) \times C R U_{65, y} \\
& R A_{k}^{s p p}=p_{k, 65} \times \sum_{i=1}^{N_{k}} R A_{i k}^{s p p} \\
& R A_{\leq 65}^{s p p}=\sum_{k=21}^{65} R A_{k}^{s p p}(1+r)^{k-65}
\end{aligned}
$$

For insured $>65$ years old:

$$
\begin{aligned}
R A_{i k}^{s p p} & =S_{\min }^{s p p} \times\left(P_{\min }^{s p p}-P_{i k}^{s p p}\right) \times C R U_{k, y} \\
R A_{k}^{s p p} & =\sum_{i=1}^{N_{k}} R A_{i k}^{s p p} \\
R A_{65}^{s p p} & =\sum_{k=66}^{T} R A_{k}^{s p p}
\end{aligned}
$$

where:

$S_{\min }^{s p p}$ : Take value 1 if $P_{\min }^{s p p}>P_{i k}^{s p p}$ and the insured fulfils legal requirements to obtain a minimum pensions; and zero, otherwise.

\section{iii. Present value of contributions for insured of the SNP:}

The only contributors are the 64 years old or younger insured.

$$
\begin{aligned}
V P_{k}^{s n p} & =(14 \times 0.13) \sum_{j=1}^{65-k} \sum_{i=1}^{N_{k}} d_{i k}^{s n p} \times Y_{i k} \times p_{k, k+j} \times(1+r)^{-j} \\
V P^{s n p} & =\sum_{k=21}^{64} V P_{k}^{s n p}
\end{aligned}
$$

\section{iv. Actuarial reserve for insured of the new multi-pillar system}

For insured $\leq 65$ years old:

$$
\begin{aligned}
& R A_{k}^{m i x}=S_{\min }^{m i x} \times\left(P_{\min }^{m i x}-P_{i k}^{m i x}\right) \times C R U_{65, y} \\
& R A_{k}^{m i x}=p_{k, 65} \times \sum_{i=1}^{N_{k}} R A_{i k}^{m i x} \\
& R A_{\leq 65}^{m i x}=\sum_{k=21}^{65} R A_{k}^{m i x}(1+r)^{k-65} \\
& R A_{s o b, k}^{m i x}=\sum_{j=1}^{65-k} C R U_{k}^{s o b}\left(1-p_{k, k+j}\right) \tilde{N}_{k}\left(P_{s o b}^{m i x}-\theta_{\text {mix }} \tilde{Y}_{k}\right)(1+r)^{-j} \\
& R A_{s o b}^{m i x}=\sum_{k=21}^{64} R A_{s o b, k}^{m i x}
\end{aligned}
$$


For insured $>65$ years old:

$$
\begin{aligned}
& R A_{i k}^{m i x}=S_{\min }^{m i x} \times\left(P_{\min }^{m i x}-P_{i k}^{m i x}\right) \times C R U_{k, y} \\
& R A_{k}^{m i x}=\sum_{i=1}^{N_{k}} R A_{i k}^{m i x} \\
& R A_{>65}^{m i x}=\sum_{k=66}^{T} R A_{k}^{m i x}
\end{aligned}
$$

And total actuarial reserve for insured is:

$$
R A_{\text {mix }}=R A_{\leq 65}^{\text {mix }}+R A_{s o b}^{\text {mix }}+R A_{>65}^{\text {mix }}
$$

where:

$\tilde{N}_{k}$ : Number of individuals of current age $k$, with $\tilde{Y}_{k}<P_{\text {sob }}^{\text {mix }} / \theta_{\text {mix }}$.

$\tilde{Y}_{k}:$ Average wage of individuals of current age $k$, with $\tilde{Y}_{k}<P_{\text {sob }}^{\text {mix }} / \theta_{\text {mix }}$.

As the SNP, the multi-pillar system provides a minimum pension for survivors of value $P_{s o b}^{\text {mix }}$. However, the portion that is guaranteed by the State is the additional capital needed to finance $P_{s o b}^{m i x}$ after the insurance firm granted a pension of value $\theta_{m i x} Y_{i k}<P_{s o b}^{m i x}$. This estimation implicitly assumes that insured always meet the legal requirements to obtain a survival pension.

Finally, insured older than 65 (at December 2006) receive the largest pension that resulted from the comparison between the multi-pillar pension and the original system's pension. This assumption is necessary to not affect the rights of workers who have already reached retirement age.

\section{v. Present value of contributions for insured of the new multi-pillar system:}

$$
\begin{aligned}
V P_{k}^{m i x} & =(14 \times \beta) \sum_{j=1}^{65-k} \sum_{i=1}^{N_{k}} d_{i k}^{m i x} \times Y_{i k} \times p_{k, k+j} \times(1+r)^{-j} \\
V P^{m i x} & =\sum_{k=21}^{64} V P_{k}^{m i x}
\end{aligned}
$$

